Biochemical and Biophysical Research Communications

July $2004 ; 320(2): 592-598$

http://dx.doi.org/10.1016/i.bbrc.2004.06.009

(c) 2004 Elsevier Inc. All rights reserved.
Archimer http://www.ifremer.fr/docelec/ Archive Institutionnelle de l'Ifremer

\title{
Oyster vasa-like gene as a marker of the germline cell development in Crassostrea gigas
}

\author{
C. Fabioux ${ }^{a}, b$, A. Huvet ${ }^{a^{*}}$, C. Lelong ${ }^{c}$, R. Robert ${ }^{a}$, S. Pouvreau ${ }^{a}$, J. Y. Daniel ${ }^{a}$, C. Minguant ${ }^{a}$ \\ and M. Le Pennec ${ }^{b}$
}

\footnotetext{
a UMR Physiologie et Ecophysiologie des Mollusques Marins, Ifremer, B.P.70, 29280, Plouzané, France

b UMR CNRS 6539, Laboratoire des Sciences de l'Environnement Marin, Université de Bretagne Occidentale, IUEM, 29280, Plouzané, France

c UMR Physiologie et Ecophysiologie des Mollusques Marins, Université de Caen, 14032, Caen Cedex, France

* Arnaud.Huvet@ifremer.fr Fax: +33-2-98-22-46-53
}

\begin{abstract}
The oyster vasa-like gene was previously demonstrated to be specifically expressed in germline cells of adult oysters Crassostrea gigas. In the present study, this gene was used as a molecular marker to establish the developmental pattern of germline cells during oyster ontogenesis, using whole-mount in situ hybridization and real-time PCR. The Oyvlg transcripts appeared to be localized to the vegetal pole of unfertilized oocytes and maternally transmitted to embryos. At early development, these maternal transcripts were observed to segregate into a single blastomere, from the $\mathrm{CD}$ macromere of 2-cell stage to the $4 \mathrm{~d}$ mesentoblast of blastula. From late blastula stage, the mesentoblast divided into two cell clumps that migrated to both sides of the larvae body and that would correspond to primordial germ cells (PGCs). Based on these results, we postulate that the germline of $\mathrm{C}$. gigas is specified at early development by maternal cytoplasmic determinants including Oyvlg mRNAs, in putative PGCs that would differentiate into germinal stem cells in juvenile oysters.
\end{abstract}

Author Keywords: Crassostrea gigas; Development; Germline; Oyster vasa-like gene; Primordial germ cells 


\section{Introduction}

Germ cells represent a unique cell type, both highly specialized and totipotent since they transmit the genetic information between generations and give rise to an entire organism (Reviewed in 1). Germ cells arise from primordial germ cells (PGCs) that originate during early development of organisms. In many animals, the differentiation of PGCs depends on a specialized region of cytoplasm, called germ plasm (Reviewed in 2). It appears as an electron dense structure due to germinal granules containing many RNAs and proteins associated with clusters of mitochondria $(1,2)$. These granules were demonstrated to be germline-specific factors deposited in the eggs during oogenesis and maternally transmitted to embryos in organisms such as Drosophila, Caenorhabditis, zebrafish and Xenopus (3, 4). The germ plasm is localized in embryos in the region where the PGCs will form, and is incorporated into these cells as they form, usually around gastrulation. In most organisms, PGCs are formed outside the future location of the gonad and migrate to the somatic part of the gonad by passive morphogenetic movements during gastrulation and/or active migration, implying gene expression and cell interactions (1, 2). In Drosophila, germ plasm ("pole plasm") is situated in the posterior pole of embryos. It undergoes a series of synchronous nuclear divisions to produce a syncytium of nuclei that cellularize to form the pole cells (PGCs), 90-120 minutes after fertilization (2). In Caenorhabditis, the germinal granules are partitioned solely in a germline blastomere, the $\mathrm{P}$ cell, from the first division. The unique PGC $\left(\mathrm{P}_{4}\right)$, formed in 24cell embryo, divides only once during embryogenesis into both $Z_{2}$ and $Z_{3}$ cells, the source of germ cells in adults.

The first germ plasm component to be identified was the vasa gene of Drosophila (5). This gene encodes a putative ATP-dependent RNA helicase in the DEAD-box protein family $(6,7)$. Vasa-related genes were isolated from many groups, including nematodes, sponges, cnidarians, amphibians, birds, fishes, and mammals (8-16). In all organisms examined, vasa 
expression was restricted to the germ cell lineage and was detected throughout development from the embryo to the adult gonad. The role of vasa in germline formation in embryos was clearly demonstrated in Drosophila, Caenorhabditis and zebrafish by functional analysis of mutation or inactivation of the vasa gene $(6,17,18)$.

In the oyster Crassostrea gigas, few data address the formation of the germline cells. Molluscs, like other protostomians such as annelids, follow a spiralian development characterized by an invariant cleavage pattern (19). The embryo is divided into blastomeres that receive a unique content of cytoplasm. Development may be tracked from the origin of blastomeres through entire development up to the formation of the definitive organs (20). However, the origin of germline is unclear in most mollusc species. In bivalves, the existence of PGCs was reported only in few species, such as Cyclas cornea, Sphaerium japonicum and Lasea rubra (21). In the clam Sphaerium, the PGCs were thought to arise from the 4d mesentoblast formed at the sixth cleavage. In C. gigas, the origin of the germline has not been established since germ cells can not be distinguished until juvenile stage (22). The orthologue of vasa gene (Oyvlg), previously characterized in C. gigas (23), could be a useful marker to study the germline development in oysters since it was demonstrated to be specifically expressed in germline cells in adult oysters both in males and females.

In the present study, we used the Oyvlg as a germline cell-specific marker to study the origin and the formation pattern of germ cells during C. gigas ontogenesis. We localized and assayed the expression of Oyvlg at different developmental stages using whole-mount in situ hybridization and real-time PCR techniques. 


\section{Materials and methods}

\section{Experimental reproduction and larval rearing}

Wild mature oysters, collected on the Atlantic coast of Brittany (France), were used for experimental breeding. All steps of fertilization and rearing were realised with $0.2 \mu \mathrm{m}$-filtered seawater. The sex of oysters was determined by microscopic examination of gametes. Sperm and oocytes were collected by stripping the gonads and oocytes were counted using Malassez slides. Oocytes from 6 females ( 40 million) and spermatozoids from 4 males were mixed in 5-L seawater cylinders $\left(2.10^{6}\right.$ eggs/L), until the appearance of the second polar body. Fertilized eggs were then washed on a nylon screen (20 $\mu \mathrm{m}$ mesh) to eliminate excess sperm, and placed in $150 \mathrm{~L}$ tanks at a density of 40 embryos/L. Larval cultures were maintained at $25^{\circ} \mathrm{C}$ and aerated with air bubbling. The rearing density was progressively reduced to 5 larvae/L and 2 larvae/L at the D larval (2 days post-fertilization (dpf)) and pediveliger (18 dpf) stages, respectively. First fixations were observed 25 days after fertilization.

Various developmental stages, identified microscopically, were sampled: oocytes before fertilization, 4-cell and 8-cell embryos (1 and 2 hours post-fertilization, respectively), morulas (3 hpf), blastulas (5 hpf), gastrulas (7 hpf), trochophores (16 hpf) and D-larvae (2 dpf), early veliger larvae (7 dpf), later veligers (14 dpf), pediveligers (18 dpf), and larvae after fixation (27 dpf). One million oysters from each developmental stage from oocytes to trochophores, and 250000 from later stages, were sampled for total RNA extraction. One million oysters from each stage from oocytes to trochophores, and 100000 from later stages, were sampled for whole-mount in situ hybridization.

\section{RNA extraction}

Total RNA was extracted from the pool of eggs, embryos and larvae sampled for each developmental stage, using TRIzol reagent (GibcoBRL) and then treated with $0.1 \mathrm{unit} / \mu \mathrm{L}$ 
DNase I (deoxyribonuclease) (Sigma) to prevent DNA contamination. RNA concentrations were measured, after DNase treatment, at $260 \mathrm{~nm}$ using the conversion factor $1 \mathrm{OD}=40 \mu \mathrm{g}$ RNA.

\section{Reverse transcription}

Reverse transcription (RT) was carried out as described in Huvet et al. (24) using oligo(dT) $)_{23}$-anchored as a primer, 200 units Moloney Murine Leukemia Virus (MMLV) reverse transcriptase (Sigma) and $2 \mu$ g total RNA from each isolated developmental stage.

\section{Real-time PCR analysis}

The level of Oyvlg transcripts expressed during oyster ontogenesis was investigated by real-time PCR using an Icycler (Biorad). Amplification of oyster Elongation Factor I (BQ426516) cDNA was performed to confirm the steady-state expression of a housekeeping gene, allowing an internal control for Oyvlg gene expression. Oyvlg- and Elongation Factor Ispecific primers were VS-S9 (5'-TCCCCGAGGAGATTCAGA-3'), VS-AS9 (5'ACGTCAGTGCAAGCACCA-3') and qfElong I (5'-ACCACCCTGGTGAGATCAAG-3'), qrElong I (5'-ACGACGATCGCATTTCTCTT-3'), respectively. Real-time PCR assays were performed, in triplicate, with $5 \mu \mathrm{L}$ cDNA (1/5 dilution) in a total volume of $15 \mu \mathrm{L}$ with each primer at $0.33 \mu \mathrm{M}, 1.5 \mu \mathrm{L}$ fluorescein, and 1X "Quantitect SYBR Green PCR kit" (Qiagen). The cycling conditions consisted of Taq polymerase thermal activation for $15 \mathrm{~min}$ at $95^{\circ} \mathrm{C}$, then 45 cycles of denaturation at $95^{\circ} \mathrm{C}$ for 30 seconds and annealing/elongation at $60^{\circ} \mathrm{C}$ for 1 min. For each individual sample, a melting curve program was carried out from $95^{\circ} \mathrm{C}$ to $70^{\circ} \mathrm{C}$ by decreasing temperature by $0.5^{\circ} \mathrm{C}$ each 10 seconds. Each run included the cDNA control, negative controls (total RNA treated with DNase I) and blank controls (water). PCR 
efficiency (E) was determined for each primer pair by performing standard curves from serial dilutions to ensure that E ranged from $99 \%$ to $100 \%$.

Calculation of relative Oyvlg mRNA levels was based on the comparative Ct method (25). The relative quantification value of the sample, normalized to the Elongation Factor I gene and relative to the control, is expressed as $2^{-\Delta \Delta \mathrm{Ct}}$, where $\Delta \mathrm{Ct}=(\mathrm{Ct}(O y v l g)-\mathrm{Ct}$ (Elongation Factor I)) and $\Delta \Delta \mathrm{Ct}=\Delta \mathrm{Ct}$ of cDNA sample $-\Delta \mathrm{Ct}$ of positive cDNA control.

Comparison of the level of Oyvlg mRNA (relative to Elongation Factor I mRNA) between developmental stages of oyster was performed by paired Student's $t$-test using SYSTAT 9.0 by SPCC.

Probe synthesis

Digoxigenin-labeled RNA sense and anti-sense probes were synthesised from the clone of

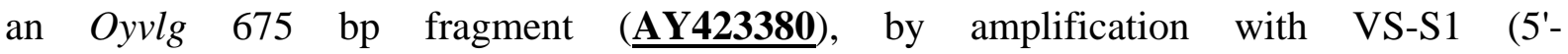
TCCAGGAACCACAAGCCCTG-3') and VS-AS4 (5'-CTGGAGCTTTCCCAAGCTTG-3') specific primers using a DIG RNA labelling kit (Roche).

\section{Whole-mount in situ hybridization}

Fixation of samples and whole-mount in situ hybridization (ISH) were performed using the protocol described by Nederbragt et al. (26) for Patella vulgata. Prehybridization was done for $6 \mathrm{~h}$ at $65^{\circ} \mathrm{C}$ in hybridization buffer (5X SSC, 50\% formamide, $100 \mu \mathrm{g} / \mathrm{ml}$ Torula RNA, 1.5\% blocking reagent (Roche), 5 mM EDTA, 0.1\% Tween 20). Sense or anti-sense probe was added $(1 \mu \mathrm{l})$ and hybridized to target overnight at $65^{\circ} \mathrm{C}$. Probes were washed away and antibody incubation was performed in a fresh solution of anti-digoxigenin antibody coupled to alkaline-phosphatase (AP) (diluted 1:5000) (Roche) for 1h. Samples were then washed and stained for 45 min in the dark with AP buffer containing 1\% (w/v) polyvinyl 
alcohol (PVA), $3.5 \mu \mathrm{l}$ NBT (Nitro blue tetrazolium; $75 \mathrm{mg} / \mathrm{ml}$ ) (Roche) and $3.5 \mu \mathrm{l} \mathrm{BCIP} \mathrm{(5-}$ bromo-4-chloro-3-indolylphosphate; $50 \mathrm{mg} / \mathrm{ml}$ ) (Roche) per $\mathrm{ml}$ of buffer. The reaction was stopped by washing twice in TBS-T (136 mM NaCl, 25 mM Tris, pH7.4, $2.7 \mathrm{mM} \mathrm{KCl,} \mathrm{0.1 \%}$ Tween). For photography, samples were dehydrated, washed twice in histoclear, and mounted in Canada balsam (Sigma). Pictures were taken with a Leitz DIAPLAN microscope with DIC optics (Nomarski) on 50 ASA Fuji Velvia film.

\section{Results and Discussion}

Oyvlg is maternally supplied to embryos

Real-time PCR analysis showed a maximum amount of Oyvlg transcripts in unfertilized oocytes (mean relative expression $=81.0 \pm 22.4$ ) and in early developmental stages, 4 -cell (75.0 \pm 12.8) and 8-cell embryos (57.2 \pm 5.8) (Figure 1). The level of Oyvlg mRNA expression dropped significantly $(\alpha=0.01)$ in the morula $(18.2 \pm 7.2)$ relative to earlier stages. The transcription of molluscan embryonic genome begins in the gastrula, and early development is supported by transcripts from the maternal genome (27). Therefore, the large amount of Oyvlg mRNA observed in unfertilized oocytes and in first cleavage stage C. gigas embryos indicated that Oyvlg transcripts were maternally synthesized and transmitted to embryos to support early development, suggesting a role in precocious specification of germ cells. In Drosophila, Hydra and zebrafish, vasa-related genes were also shown to be maternally transmitted and implied in germline differentiation in embryos before the beginning of zygotic gene expression $(5,9,18)$. 
Figure 1: Level of Oyvlg transcripts relative to Elongation Factor I transcripts in unfertilized oocytes and in various developmental stages of Crassostrea gigas analysed by real-time PCR. Bars represent standard deviation at $5 \%$ level. hpf means hour post-fertilization.

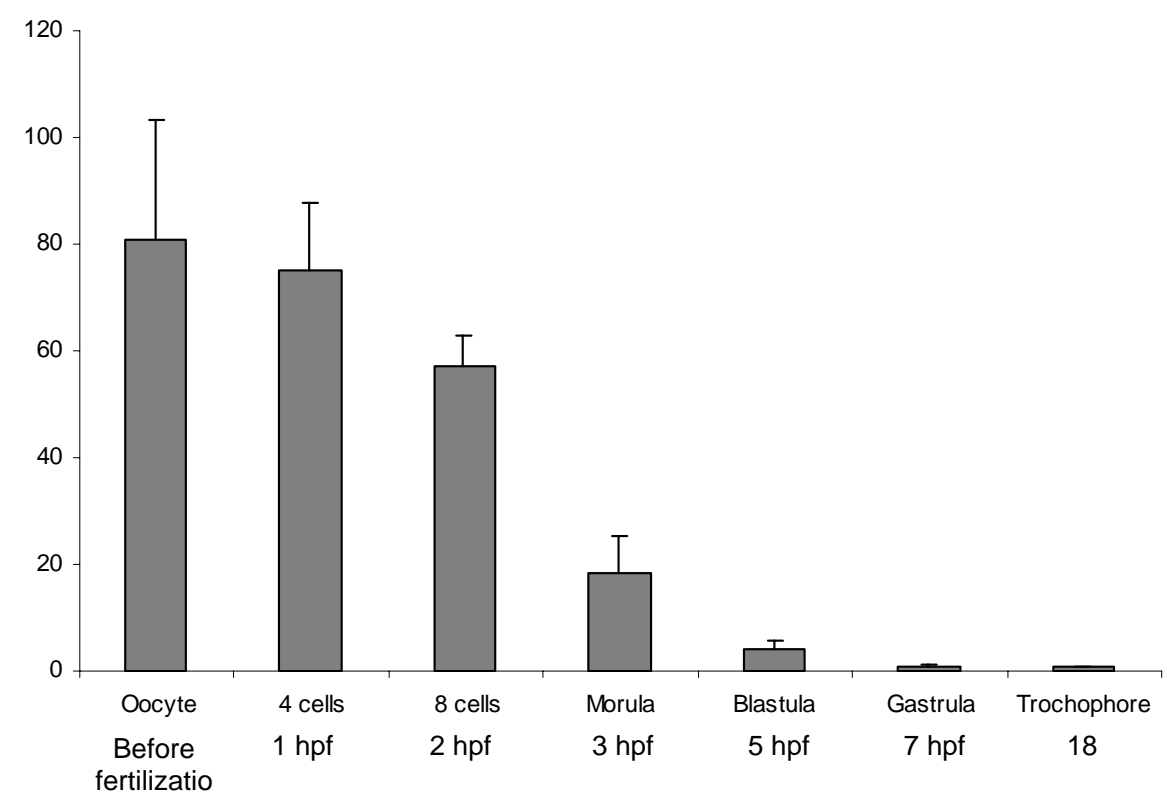

The asymmetrically localized cytoplasm could be a germ plasm

The localization of Oyvlg transcripts during embryogenesis was analysed by whole-mount ISH. In unfertilized oocytes, strong hybridization signal was localized in cytoplasmic granules at the vegetal pole of oocytes (Figure 2). The rest of each oocyte was not stained, nor was any sample hybridized to the sense probe (Figure 2). In early 2-cell and 4-cell-developmental stages a strong signal localized asymmetrically in the perinuclear cytoplasm of a single blastomere; no signal was detected in other parts of the embryos. In several organisms, including Drosophila, Caeonorhabditis and Hydra, vasa-related gene products were demonstrated to segregate in the germ plasm $(5,8,9)$. The germ plasm is a specialized cytoplasmic region of oocytes and early embryos, containing dense cytoplasmic granules, rich in maternal mRNAs and proteins $(4,28)$. The specification of germline cells during embryogenesis was demonstrated to depend on the segregation of these maternal RNAs and 
proteins in the germ plasm (2). The existence of germ plasm was postulated in the molluscs Crepidula and Shpaerium (21) based on morphological criteria, but it has never been mentioned in oyster. In the present study, the segregation of cytoplasmic granules containing Oyvlg transcripts successively in the vegetal pole of oocytes and in a single blastomere in early embryos indicate that the cytoplasmic region containing Oyvlg mRNAs could be the germ plasm. 
Figure 2: Localization of Oyvlg transcripts in unfertilized oocytes and in various developmental stages of Crassostrea gigas. Whole-mount in situ hybridization was performed with Oyvlg sense and anti-sense riboprobes. The lower panels of each line represent negative controls hybridized with sense probes. Oyvlg transcripts are detected in unfertilized oocytes and in a unique blastomere of embryos from 2-cell stage to blastula. Oyvlg mRNAs distribute in two clumps from the gastrula stage and remain in this distribution until the metamorphosis. Scale bar $10 \mu \mathrm{m}$. Magnification X 500 for stages from unfertilized oocytes to gastrula and X 200 for later larvae stages. Arrows indicated hybridization signal.

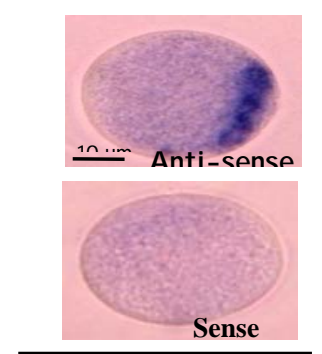

Unfertilized oocyte
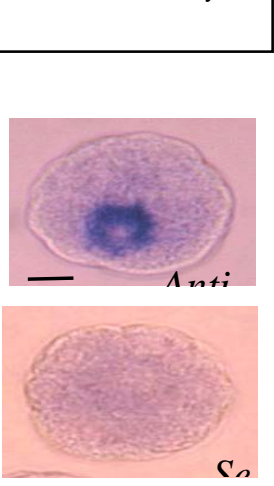

Co

Morula
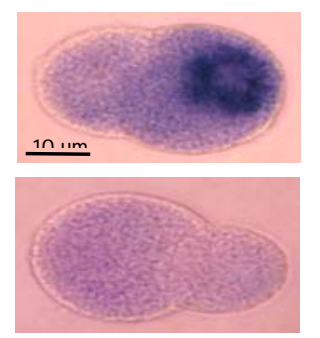

2-cell
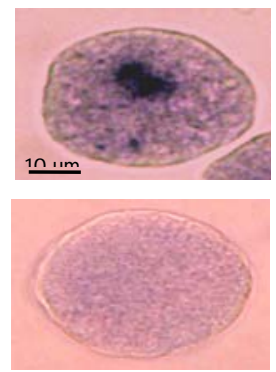

Blas Figure
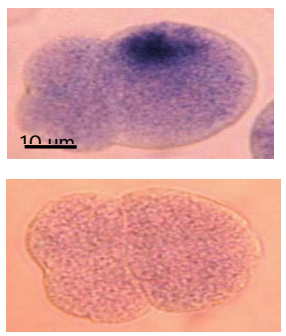

\section{4-cell}
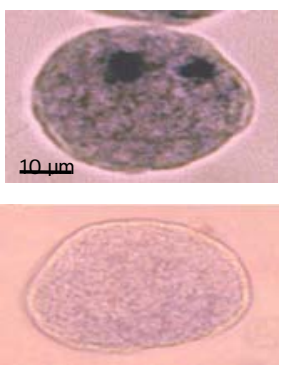

Gastrula Top view
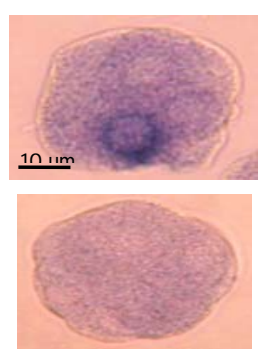

8-cell
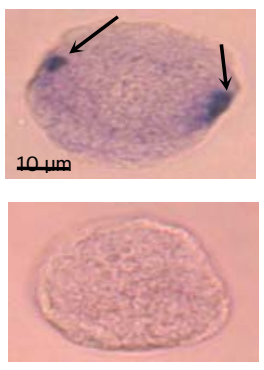

Trochophore Top view

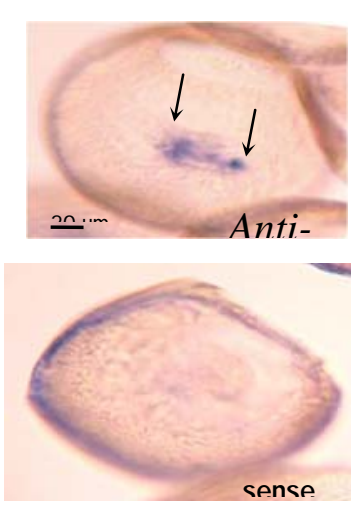

Veliger early
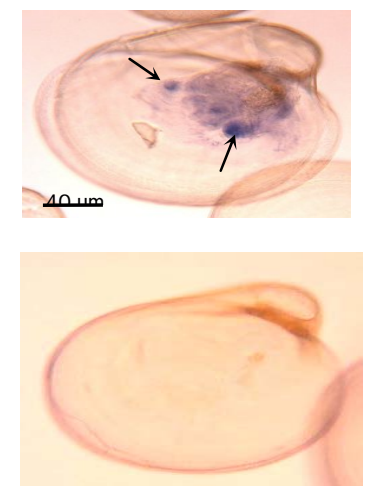

Veliger later
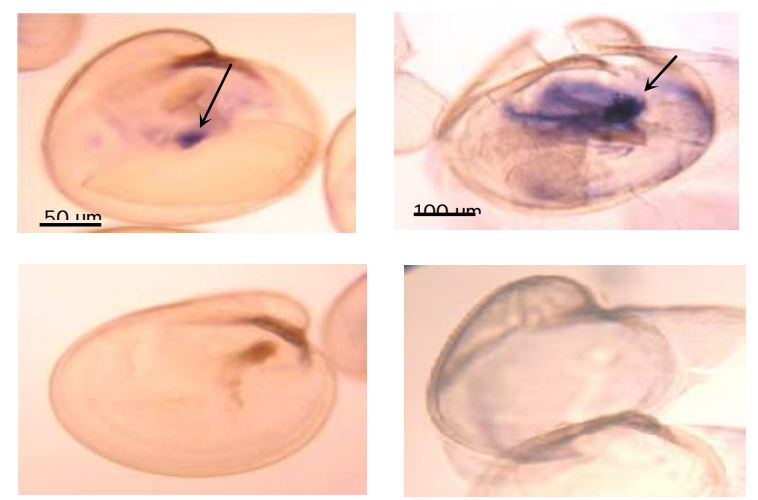

Pediveliger
Metamorphosed 
Oyvlg mRNA: a determinant of oyster germline cell fate

The localization of vasa gene products in germ plasm appeared to occur either at a protein level or at a transcript level, depending on the organism. In Drosophila, Caenorhabditis and medaka, VASA protein is a determinant of the germline and is localized in the germ plasm, while the transcripts show no specific localization in early embryos $(6,8,29)$. On the other hand, in zebrafish and Ciona, maternal vasa transcripts are germline determinants and localize in the cytoplasmic region where the PGCs will form at early developmental stages; in these species, VASA protein show no specific localization $(13,30)$. In molluscs, morphogenetic determinants of somatic lineage cells were found in the vegetal pole of uncleaved eggs and in restricted region of embryos (31). In C. gigas, we observed that Oyvlg transcripts were inherited by a single blastomere as early as the 2-cell embryo stage and segregated into a unique blastomere along all cleavage stages, while no ISH signal was detected in other cells (Figure 2). Based on these results, on the maternal transmission of Oyvlg transcripts, and on the specific expression of Oyvlg in germline cells in adult oysters (23), we postulated that Oyvlg mRNAs might be maternal determinants of germline cells in oysters as observed for zebrafish and Ciona (13, 30).

To definitively prove that Oyvlg mRNAs are germline determinants in oyster, we will need to further study the effect of inhibition of Oyvlg mRNA synthesis and the localization of OYVLG protein during early development.

\section{Primordial germ cells in oyster embryos}

In most organisms, PGCs form around gastrula stage in the region where the germ plasm is localized, and incorporate this germ plasm (1). Then, the small number of founder PGCs proliferate and migrate to the somatic part of the future gonad. In gastrula and trochophore oyster larvae, we observed two hybridization signals on the right and left of the midline of the 
larvae (Figure 2, top view). From early veliger (7 dpf) to metamorphosed larvae (27 dpf), Oyvlg transcripts clearly localized in two stained clusters located in both sides of oyster larval body (Figure 2). This dual localization of Oyvlg transcripts in oyster larvae corresponded to the previous description of "germinal primordium" made by Lubet et al. (22) in mussel postlarvae. "Germinal primordium" were described as two cellular clusters, symmetrical about the midline of the mussel larval body, located between the kidney and the posterior part of the digestive gland. Likewise, our results suggest that these symmetrical clumps, stained by Oyvlg probe, are oyster primordial germ cells. These PGCs, the number of which was undetermined, appeared to form during gastrulation and were detected in both sides of veliger larvae body.

By whole-mount ISH, Oyvlg transcripts were detected throughout oyster development including in later stages, while by real-time PCR, Oyvlg expression steadily and significantly decreased through development, reaching a very low level in gastrula $(0.8 \pm 0.4)$ and trochophore stages $(0.7 \pm 0.3)(\mathrm{P}<0.01$, Figure 1$)$ and finally becoming essentially undetectable from $\mathrm{D}$ larval stage to metamorphosis (mean value $<0.1$ ). This might be due to the very low number of PGCs compared to the total number of cells in oyster larvae, as observed in many organisms like Caenorhabditis and Drosophila, in which one and approximately 15 PGCs are formed during embryogenesis, respectively.

\section{Primordial germ cells of oyster would arise from $4 d$ mesentoblast}

Development of molluscs, like other protostomians such as annelids, follows a spiral cleavage pattern (19). The egg is divided into blastomeres by extremely regular and invariant cleavages giving a precise cytoplasmic segregation $(20,21)$. On this basis, cell-lineage maps have been constructed, indicating the origin of most organs in some mollusc species, such as Patella vulgata (32). However, the origin of the germline remains unclear in most molluscs. 
In Sphaerium and Patella, germ bands were assumed to arise from $4 \mathrm{~d}$ micromere called mesentoblast, formed during the sixth cleavage $(33,34)$. The mesentoblast gives rise to endomesoderm that is thought to differentiate into heart, kidney, and gonad in adults. Based on these assessments and on the localization of Oyvlg transcripts during oyster development, we postulate on the developmental pattern of $C$. gigas germline from fertilization to metamorphosis using Oyvlg as a marker of germline (Figure 3). During the second cleavage, the Oyvlg transcripts appeared localized to the D quadrant, defined as the largest one (31). According to the disposition of blastomeres (32), we suggest that from third to sixth cleavages, the putative germ plasm we observed segregated successively in $1 \mathrm{D}, 2 \mathrm{D}$ and $3 \mathrm{D}$ macromeres and in the $4 \mathrm{~d}$ micromere, respectively (Figure 3). In the gastrula, Oyvlg mRNAs were distributed in two clumps symmetric relative to the midline of larvae. These clumps could correspond to the $\mathrm{Mr}$ and $\mathrm{Ml}$ cells arising from the division of 4d mesentoblast, described in Patella and demonstrated to be the paired stem cells of mesodermal germ bands (32). The sinking of the $\mathrm{Mr}$ and $\mathrm{Ml}$ cells into blastocoel could explain the weak intensity of the hybridization signal observed in trochophore oyster larvae (Figure 3). These cells would then proliferate to give putative PGCs and migrate by undetermined ways to the anterior and the posterior sides of the body of later stage larvae and first post-larvae stage (Figure 3). In juvenile oysters, PGCs would differentiate into two groups of germinal stem cells (GSCs) that would correspond to the two mesodermal germinal buds situated in the pericardic region previously described in molluscs (35). When juvenile oyster reach sexual maturity, GSCs would proliferate intensively to form the gonadic tubules that develop from the pericardic region toward the anterior part of the oyster, symmetrically compared to the midline of the body (22). Gonadic tubules branch out in complex networks and invade the conjunctive tissue around the digestive gland to form the gonad (35). After spawning, gonad regresses and only small clusters of GSCs persist in few remaining tubules dispatched in conjunctive tissue 
during the resting period (23). These GSCs will proliferate again at the beginning of the following reproductive cycle from remaining tubules to form the new gonad (23).

\section{Acknowledgements}

The authors are grateful to J.C. Cochard for his support during the course of this work. The authors are indebted to all staff of the Argenton Ifremer station for breeding oysters and rearing larvae. We thank A. Le Herisse for giving access to microscopy equipment. We are grateful to R. Carnegie (VIMS, Virginia, USA) for his help in editing the English language. 
Figure 3: Schematic summary of Crassostrea gigas germline development during embryogenesis, from unfertilized oocytes to metamorphosed larvae. Orange zones represent regions of cytoplasm containing germline determinants from oocyte to blastula stages and PGCs from gastrula stage. Arrowheads represent the direction of cell migation.

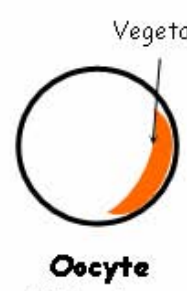

Side view

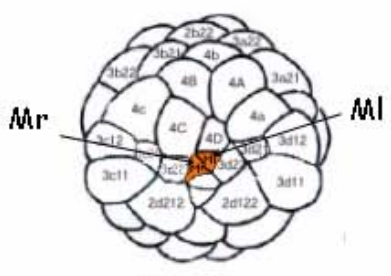

Blastula, top

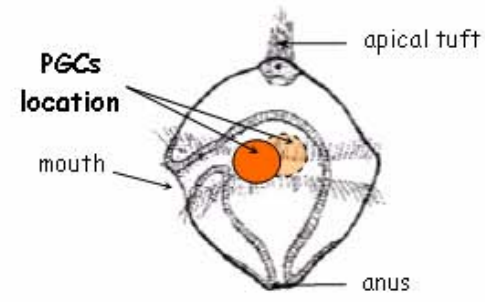

Trochophore, side

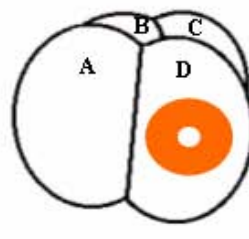

4-cell, side

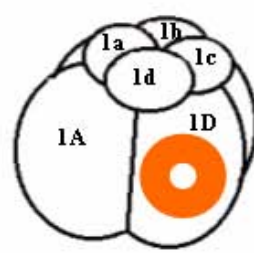

8-cell, side

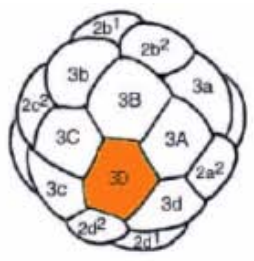

32-cell, top

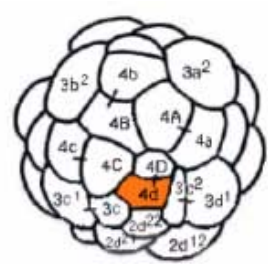

Morula, top

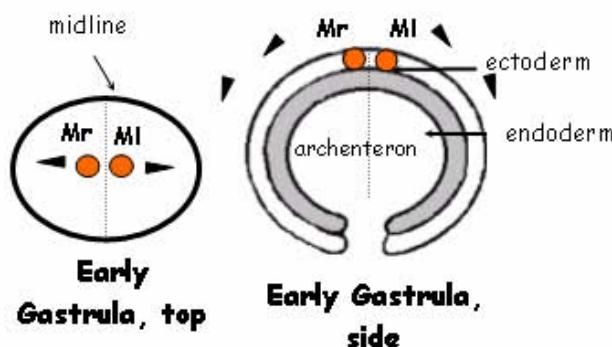

side

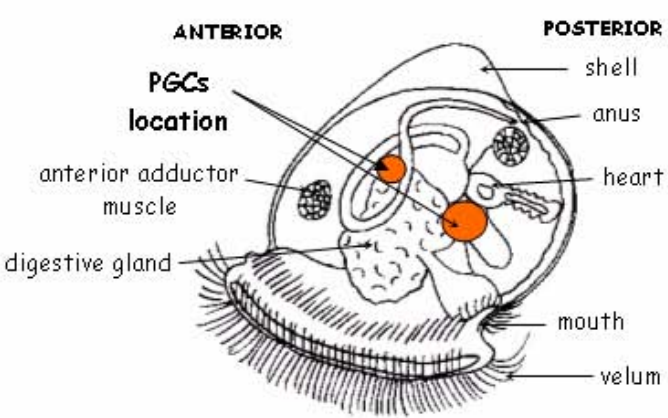

Veligen 14 dpf, side

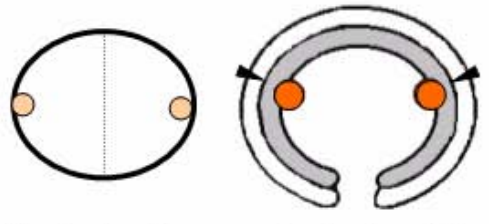

Gastrula, top Gastrula, side

Figure 3 


\section{References}

1. Wylie, C. (1999) Cell 96, 165-174.

2. $\quad$ Saffman, E. E., and Lasko, F. (1999) Cellular and Molecular Life Sciences 55, 11411163.

3. $\quad$ Rongo, C., and Lehmann, R. (1996) Trends Genet. 12, 102-109.

4. $\quad$ Eddy, E. M. (1975) International Revue of Cytology 43, 229-281.

5. $\quad$ Hay, B., Jan, L. Y., and Jan, Y. N. (1988) Cell 55, 577-587.

6. $\quad$ Lasko, F., and Ashburner, M. (1988) Nature 335, 611-617.

7. $\quad$ Liang, L., Diehl-Jones, W., and Lasko, P. (1994) Development 120, 1201-1211.

8. Roussel, D., and Bennett, K. L. (1993) Proceedings of the National Academy of Sciences USA 90, 9300-9304.

9. Mochizuki, K., Nishimiya-Fujisawa, C., and Fujisawa, T. (2001) Development Genes and Evolution 211, 299-308.

10. Komiya, T., Itoh, K., Ikenishi, K., and Furusawa, M. (1994) Developmental Biology 162, 354 - 363.

11. Tsunekawa, N., Naito, M., Sakai, Y., Nishida, T., and Noce, T. (2000) Development 127, 2741-2750.

12. $\quad$ Olsen, L. C., Aasland, R., and Fjose, A. (1997) Mechanisms of Development 66, 95105.

13. Yoon, C., Kawakami, K., and Hopkins, N. (1997) Development 124, 3157-3166.

14. Fujiwara, Y., Komiya, T., Kawabata, H., Sato, M., Fujimoto, H., Furusawa, M., and Noce, T. (1994) Poceedings of the National Academy of Sciences of the United states 91, 12258-12262.

15. Castrillon, D. H., Quade, B. J., Wang, T. Y., Quigley, C., and Crum, C. P. (2000) Proceedings of the National Academy of Sciences 97, 9585-9590.

16. Yoshizaki, G. S., S.;Tominaga, H.;Takeuchi, T. (2000) Molecular Reproduction and Development 55, 364-371.

17. Kuznicki, K. A., Smith, P. A., Leung-Chiu, W. M., Estevez, A. O., Scott, H. C., and Bennett, K. L. (2000) Development 127, 2907-2916.

18. Knaut, H., Pelegri, F., Bohmann, K., Schwarz, H., and Nuesslein-Volhard, C. (2000) Journal of Cell Biology [J. Cell Biol.] 149, 875-888.

19. Wilson, E. B. (1892) Journal of Morphology 6, 361-481.

20. Verdonk, N. H., and Van den Biggelaar, J. A. M. (1983) in The Mollusca. Development (N.H. Verdonk, J. A. M. V. d. B., Tompa, A.S., Ed.), pp. 91-122 Academic Press, New york.

21. Dohmen, M. R. (1992) Microscopy Research and Technique 22, 75-102.

22. Lubet, P., Herlin-Houtteville, P., and Matthieu, M. (1976) Bulletin de la Société Zoologique de France 101, 22-27.

23. Fabioux, C., Pouvreau, S., Le Roux, F., and Huvet, A. (2004) Biochemical and Biophysical Research Communications 315, 897-904.

24. Huvet, A., Daniel, J. Y., Quéré, C., Dubois, S., Prudence, M., Van Wormhoudt, A., Sellos, D., Samain, J. F., and Moal, J. (2003) Aquaculture 228, 321-333.

25. Livak, K. L., and Schmittgen, T. D. (2001) Methods 25, 402-408.

26. Nederbragt, A. J., Van Loon, A. E., and Dictus, W. J. A. G. (2002) Developmental Biology 246, 341-355.

27. Collier, J. R. (1983) in The Mollusca. Development (Tompa, A. S., Ed.), pp. 253-297 Academic Press, New york. 
28. Lasko, F., and Ashburner, M. (1990) Genes Development 4, 905-921.

29. Shinomiya, A., Tanaka, M., Kobayashi, T., Nagahama, Y., and Hamaguchi, S. (2000) Development Growth and Differentiation 42, 317-326.

30. Fujimura, N., and Takamura, K. (2000) Development Genes and Evolution 210, 64-72.

31. Verdonk, N. H., and Cather, J. N. (1983) in The Mollusca. Development (Tompa, A. S., Ed.), pp. 215-252 Academic Press, New york.

32. Dictus, W. J. A. G., and Damen, P. (1997) Mechanisms of Development 62, 213-226.

33. Lartillot, N., Lespinet, O., Vervoort, M., and Adoutte, A. (2002) Development 129, 1411-1421.

34. Woods, F. H. (1931) Journal of Morphology and Physiology 51, 545-595.

35. Tardy, J. (1970) Bulletin de la Société Zoologique de France 95, 407-427. 